\title{
Enrique Dussel e a filosofia da libertação
}

\section{Enrique Dussel and the Philosophy of Liberation}

DOI: 10.12957/ek.2021.60822

\author{
Klinger Scoralick ${ }^{1}$ \\ Pontifícia Universidade Católica - RJ \\ scoralickk@yahoo.com.br \\ https://orcid.org/0000-0002-3265-6720
}

\section{RESUMO}

A filosofia de libertação proposta por Enrique Dussel apresenta-se como uma crítica aos fundamentos filosóficos da modernidade que se encontram atrelados à ideia da dominação, da conquista, da totalidade. Propondo uma filosofia atenta à exterioridade do outro desde sua positividade - que se encontra excluída da ordem mundial, e que grita e reclama justiça - Enrique Dussel lança as bases de um novo modelo de racionalidade, fundamentalmente ético, voltado para a periferia.

Palavras-chave: Filosofia da libertação. Enrique Dussel. Modernidade. Alteridade. Ética.

\begin{abstract}
The Philosophy of Liberation proposed by Enrique Dussel presents itself as a critique of the philosophical foundations of Modernity that are linked to the idea of domination, conquest, and totality. Proposing a philosophy that is attentive to the exteriority of the other from its positivity - which is excluded from the world order, and which cries out and demands justice - Enrique Dussel lays the foundations for a new model of rationality, fundamentally ethical, facing the periphery.
\end{abstract}

Keywords: Philosophy of Liberation. Enrique Dussel. Modernity. Alterity. Ethics.

\footnotetext{
${ }^{1}$ Doutorando em Filosofia pela Pontifícia Universidade Católica do Rio de Janeiro.
} 
Cuando nos volvemos a la realidad, como exterioridad, por el solo hecho de ser una realidad histórica nueva, la filosofía que de ella se desprende, si es auténtica, no podrá menos que ser igualmente nueva. Es la novedad de nuestros pueblos lo que se debe reflejar como novedad filosófica y no a la inversa.

\section{Enrique Dussel}

A América realiza o que pensa a Europa, diz Juan Bautista Alberdi em uma lição por ele proferida em 1842, que se intitula Ideias para presidir a elaboração do curso de filosofia contemporânea, na qual Alberdi afirma a importância de se produzir um pensamento novo, isto é, uma filosofia própria, nacional, entendida desde as necessidades e questões nascidas da América Latina. A preleção de Alberdi, dirigida ao Colégio de Humanidades de Montevideo, se tornará um marco importante para a filosofia da libertação, movimento filosófico que se tornou mundialmente conhecido nos anos 1960 e 1970 - fundamentalmente através da obra de Enrique Dussel (1934-). Esse pensamento novo, produzido desde a periferia do mundo, a partir de e para uma geografia política, cultural e econômica não-hegemônica do planeta, impõe-se como um gesto de desobrigação ou de desobediência em se pensar o ser e o não-ser sob o paradigma da verdade clássica, da subjetividade moderna e da trama que lhe é inerente, que mostrou sua face, historicamente, através da invasão, da conquista, do domínio, da ocupação, da violência, da escravagismo, da opressão e da colonização da América e de tantos outros povos periféricos ao redor do mundo - ações que seguem reverberando seus efeitos no ethos próprio desses povos. A filosofia da libertação volta-se para a condição histórica, material da América Latina - marcada pela pobreza, miséria, exclusão, exploração, fome etc. Não obstante, não se trata de um discurso de ordem meramente regional, mas sim que se projeta para o mundo, na medida em que se propõe a pensar o problema universal do encobrimento da alteridade, do periférico subjugado, obliterado, esquecido em detrimento da totalidade globalizante. Em questão encontra-se o outro da Europa, 
especificamente a América Latina, essa margem periférica da história - como diz Leopoldo Zea em América en la historia (1957) - e da história da filosofia, que busca resistir a todo essencialismo e a todo discurso metafísico totalizante que pretende subsumi-la.

"Filha do logos", onde o ser é o visto, a cultura moderna, segundo Dussel, estabelece sua ordem, sua medida e o seu progresso desde aquilo que marca o início e fim de todo pensar no Ocidente e que permite sustentar desde Parmênides que pensar e ser é o mesmo (fragmento 3). O ser é, verdade idêntica a si mesma - e o todo é uma unidade em si mesma. O que se encontra dentro desta unidade "é”" (hegemônico), o que está fora "não é" (periférico). O outro - sempre um não-ser - não tem garantida sua existência; não se insere no todo e define-se por negação, nada. A filosofia da libertação visa a interromper esta lógica de aniquilação histórica promovida pelos ideais, os mais elevados, da modernidade. Por ser uma "filha mestiça", "nova, única, exterior a toda outra cultura e com a exigência de dever descobrir-se hoje em sua exterioridade real" (DUSSEL, 1986, p. 239), a América Latina reivindica seu lugar ao sol na história mundial ao afirmar ser dona de uma linguagem nova e capaz de oferecer um sentido diverso à realidade, projetando seu olhar desde a periferia e compreendendo a importância de dizer o seu nãoser, seu "não", sua resistência, sua "moralidade" própria. "O télos ou bem de uma cultura, de uma totalidade, não pode ser necessariamente o fundamento definitivo da moralidade dos atos. Ele o será apenas "por enquanto", até se descobrir o Outro negado nesse tipo de sistema" (DUSSEL, 1995, p. 111). De modo programático, Dussel propõe em sua obra descortinar, de-colonizar, certas "categorias encobridoras" que fundam a filosofia moderna - racionalidade europeia - e sua ideologia de dominação que impactaram violentamente a periferia latino-americana. Para tanto, ele volta sua atenção à exterioridade desse mundo que escapa ao horizonte de sentido europeu e moderno, para essa margem que possui corporeidade própria e é marcada pelo sofrimento e pela aniquilação. Desse modo, a filosofia da libertação lança-se de encontro ao modelo cultural racionalista que se traduziu em conquista, invasão e morte.

Segundo Dussel, a modernidade, assim como a história mundial, inicia-se no ano de 1492, quando a Europa se estrutura como capital do sistema político e econômico mundial, e universaliza-se um modelo de racionalidade que se faz guiar pelas vozes de uma noção de subjetividade que advém desse centro do mundo. Fundamentalmente, a 
modernidade é um fenômeno de origem europeia, que compreende que "tudo o que não é europeu é bárbaro" (ALBERDI, 2017, p. 32); aliás, a filosofia da libertação é uma filosofia bárbara (DUSSEL, 1986, 213). Por sua vez, a filosofia, tal qual a conhecemos, e toda cultura em torno dela, são reflexos civilizatórios do eurocentrismo encobridor ${ }^{2}$. Considerando-se tais premissas, Dussel afirma que o ego cogito cartesiano, esse alicerce o mais sólido da modernidade, é a expressão do ego conquiro de Hernán Cortés (o conquistador de Yucatán) ou de Pizzaro. O eu conquisto atravessa e consolida a protohistória da subjetividade moderna, em que o sujeito, o eu, sustenta e afirma o mundo, impondo-o ao outro, desde sua racionalidade universal, em um movimento de aniquilação da diferença. Voltado sobre si, o sujeito pensante, europeu, "descobre" a realidade com a qual ele se depara e dá a ela um nome, tomando-a como extensão de sua verdade; em seu fervor racional, o sujeito pensante desconsidera qualquer possibilidade de significação da realidade que escape ao seu próprio ser, permanecendo, por isso, fechado em si mesmo, totalizando-se e totalizando:

Passou desapercebido aos filósofos que, devido a este fato, o problema da "universalidade" foi encarado pela Modernidade de um modo nunca abordado anteriormente. O "eurocentrismo" consiste exatamente em confundir ou identificar aspectos da universalidade abstrata (ou até transcendental) humana em geral com momentos da particularidade europeia, de fato a primeira particularidade mundial (em outras palavras, a primeira universalidade humana concreta). A cultura, a civilização, a filosofia, o subjetivismo e outros elementos moderno-europeus passaram a ser considerados pura $e$ simplesmente (universal humano abstrato) como cultura, civilização, filosofia, subjetivismo etc. Grande parte dos êxitos da Modernidade não representam uma criatividade exclusivamente europeia; mas, sim, uma constante dialética de choque e contrachoque, efeito e contra-efeito, entre a Europa moderna e sua periferia, até mesmo no tocante ao que poderíamos denominar de formação paulatina do subjetivismo propriamente moderno enquanto tal. $\mathrm{O}$ ego cogito também já está insinuando o relacionamento com uma proto-história do século XVI apontada pela ontologia de Descartes, mas que não surgiu do nada. Precede-a o ego conquiro (eu conquisto), em forma de "eu prático" (practical self). Em 1521, Hermán Cortes já está antecipando por mais de um século ao

\footnotetext{
${ }^{2}$ A modernidade reúne em sua identidade elementos da periferia, da barbárie, tendo sido formada mediante uma articulação dialética não tão senhora de si mesma, uma vez que os elementos ou fenômenos atribuídos originariamente a ela são determinações e contradeterminações de sua posição central em relação a uma dada diferença. O outro (bárbaro, periférico) é parte constitutiva da ordem dominante, hegemônica, de sua racionalidade.
} 
Discurso do método (1636). Descartes estudou em La Flêche, colégio jesuíta, ordem religiosa amplamente radicada na América, África e Ásia daquele tempo. O "bárbaro" era, então, um contexto obrigatório para toda reflexão sobre o subjetivismo, a razão e o cogito (DUSSEL, 1995, p. 87-88).

O desdobramento do modus operandi da modernidade - encobridor da exterioridade, sob uma violência não apenas epistemológica - que se ancora na noção de subjetividade, alcança, segundo Dussel, seu ápice com a fillosofia de Hegel (1770-1831), para o qual a razão tudo engloba, isto é, totalidade que circunscreve a multiplicidade em uma unidade. Hegel defende uma maneira de raciocinar, uma razão, que tem por objetivo captar e reconhecer a universalidade na diversidade ${ }^{3}$. Trata-se de uma lógica capaz de dar conta da exposição (die Darstellung) do Absoluto em sua multiplicidade; e por este entremeio ele compreende a história da filosofia e a própria filosofia. As determinações específicas dos objetos não são tomadas isoladamente, como na representação. O diverso (particular) é absolutamente necessário e não elimina a possibilidade do uno. Há, segundo Hegel "um nexo essencial no movimento do espírito pensante, onde domina a razão" (HEGEL, 1989, p. 100). Há um patrimônio da razão, "corrente sagrada que conserva e transmite tudo quanto o mundo produziu antes de nós” (HEGEL, 1989, p. 88). Templo da memória, a razão deixa um vestígio, um rastro de princípios que se conservam, pois estes dizem respeito à verdade. E a verdade é eterna. Cabe ao pensamento, ao conceito, preservar, não como coletânea de noções, esta verdade, arrancando-a da profundidade do espírito, e portando-a à consciência (superação da abstração e formalidade do entendimento). Passagem do (mais) abstrato ao (mais) concreto/profundo que se mostra tanto mais rica quanto mais desenvolvida (nova, moderna) for a filosofia: ulterior determinação (HEGEL, 1989, p. 113). Com Hegel, sobremaneira, o outro não é o outro real, exterior, mas um outro de si-mesmo, desdobrado e englobado na totalidade dominante da razão (europeia), que representa a "existência geográfica e antropológica do espírito [absoluto]" (HEGEL, 1997, p. 309) - e faz justificar, consequentemente, a violência colonialista do povo dominador do mundo [Weltbeherrschende] contra os

\footnotetext{
${ }^{3} \mathrm{O}$ tratamento oferecido por Hegel à filosofia aponta para a necessidade de superação da cisão dos opostos assumida desde a modernidade (sujeito e objeto, forma e conteúdo). O pensamento especulativo busca assumir em si a diferença em suas determinações e compreendê-la enquanto unidade dialética.
} 
"povos bárbaros", que não possuem direito algum [rechtlos]. Nesses termos, em Princípios da filosofia do direito (§ 347), Hegel afirma o seguinte sobre o povo europeu:

Tal povo é o povo que na época correspondente domina a história universal. [...] [E] em face do direito absoluto que lhe cabe como representante do grau atual do desenvolvimento do espírito do mundo, nenhum direito tem os outros povos que, tais como aqueles que já representaram uma época passada, não são nada na história universal (HEGEL, 1997, p. 309).

Em Hegel não há nada que exerça a função de uma exterioridade à própria consciência. Conceito e objeto estão contidos na própria consciência e a consciência se verifica a si mesma. A diferença (exterioridade) é sempre aparente. O movimento de irmais-além, da dialética hegeliana, não abandona a consciência (o absoluto como espírito) e a aparente transcendência é eterno retorno a si. Pois, o movimento dialético hegeliano - apesar de partir do factum aristotélico, em direção ao que está oculto -, é in-volutivo, em direção à própria consciência; imanente, até o saber absoluto; Eu como princípio e fundamento. A dialética hegeliana é uma totalidade imanente, "imanência como subjetividade" (DUSSEL, 1986, p. 97). No sistema hegeliano "a subjetividade absoluta abarcou tudo dentro de si" (DUSSEL, 1986, 123). Constituiu-se como totalidade totalizada. Contrapondo-se a uma das máximas de Aristóteles, o idealismo hegeliano finda por concluir que nada existe na experiência que antes não tenha estado no intelecto. Em Hegel

\footnotetext{
foi suprimida a posição pensar-objeto pensado, conceito-essência, saber-ser. Da mesma maneira, ter-se-ia anulado a oposição moderna de sujeito e objeto. Isto quer dizer que nos encontraríamos nada mais e nada menos do que com a superação da modernidade em pleno século XIX [...]. [No entanto] o sujeito que se opõe a um objeto aparece já dentro de uma totalidade que não pode senão ser chamada de 'subjetividade absoluta'. [Esta] aparente superação da subjetividade de Kant e de seus sucessores vem a ser, deste modo, a subjetividade mais atrevida que a filosofia jamais expressou (DUSSEL, 1986, p. 99).
}

O absoluto, originariamente em si, desdobra-se em sua própria interioridade, involução intra-consciencial. Trata-se de uma dialética involutiva, sem exterioridade real. Todo e qualquer processo evolutivo natural (exterioridade) não é senão o desdobramento interno da totalidade, sempre total e totalizando-se, em que "o sistema cumpre-se totalmente na interioridade da subjetividade: o pensar é o ser; a objetividade do objeto ou a coisa é posta, como determinação finita pela subjetividade absoluta, incondicionada; 
trata-se do próprio ser" (DUSSEL, 1986, p. 126). Com efeito, a subjetividade moderna, que encontra em Hegel sua manifestação mais elevada, é, conforme afirma Dussel, uma das expressões mais pungentes do eurocentrismo e da noção de totalidade que a faz acompanhar - fenômeno da racionalização que permitiu invadir territórios estrangeiros e determinar critérios universais que justificassem sua dominação.

\begin{abstract}
O mais grave é que esta ontologia [hegeliana] diviniza a subjetividade europeia conquistadora que vem dominando o mundo desde sua expansão imperial no século XV. "O ser é, o não-ser não é". O ser é a razão europeia, o não-ser são os outros humanos. A América latina e toda a 'periferia' ficam, por isso, definidas como o puro futuro, como o não-ser, como o irracional, o bárbaro, o inexistente. A ontologia da identidade da razão e da divindade com o ser termina por fundamentar as guerras imperiais de uma Europa dominadora de todos os outros povos, constituídos como colônias, neocolônias, "dependentes" em todos os níveis de seu ser. A ingênua ontologia hegeliana termina sendo a sábia fundamentação do genocídio dos índios, dos africanos e asiáticos. A subjetividade do ego cogito transforma assim na "vontade de poder" tudo quanto essa subjetividade divinizada pretenda, em nome de sua razão incondicionada (DUSSEL, 1986, p. 124).
\end{abstract}

Os apontamentos feitos por Dussel indicam que a modernidade forjou uma identidade sob uma falsa noção de universalidade, de modo provinciano, regional sob exclusão da periferia mundial como fonte constitutiva do chamado "eu moderno". É preciso contestar esse pressuposto que sustenta o mundo moderno e que oculta sua alteridade. A racionalidade europeia não é causa da modernidade, mas seu efeito - tendo como princípio o apoderar-se, a conquista. Pois, compreende-se que o ano de 1492 constitui-se como o marco inicial da proto-história do ego cogito, uma vez que a dominação e expansão européia são o princípio de efetivação do "eu moderno", da sua razão e, não o contrário; a condição sine qua non da modernidade é o pensar conquistador, ego conquero, que tem por fundamento a aniquilação da diferença. Será, pois, contra esta razão dialética in-volutiva, que em Hegel alcança o status de uma "razão quase enlouquecida" (KONDER, 1991), que a filosofia da libertação incidirá seu discurso, propondo uma razão analética - que, contrariamente, tem como ponto de partida justamente a facticidade negada até então - em um movimento de afirmação do Outro, o não-ser, movimento ético por excelência. Como se configura essa razão antitética?

Dussel diz que é preciso estabelecer um pensamento analético, ana-dia-lético. Ele faz uma distinção entre a "verdadeira dia-lética", que possui um ponto de sustentação ana-lético, e uma "falsa dialética", essencialmente dominadora e imoral, que é "simplesmente um movimento conquistador: dia-lético" (DUSSEL, 1986, p. 196-197). 
Para além de Hegel, Dussel irá afirmar que para se descobrir o conteúdo da realidade "é necessário encaminhar-se por uma 'investigação histórica', na qual a realidade se mostre", em oposição à toda filosofia "que toma como "o real somente no conceito e como pura ideia"” (DUSSEL, 1986, p. 134). O método analético define-se como projeto de ultrapassagem epistemológica do horizonte de sentido que se atém à ontologia em direção ao outro-totalmente-outro - considerando a precedência do outro, isto é, a ética como filosofa primeira. "A analética histórica, que se funda no outro como exterioridade livre e sempre de algum modo incondicionado deve ser analisada a partir do caminho aberto por Lévinas" (DUSSEL, 1986, p. 216), para o qual a totalidade é a realização da unidade do mesmo (mesmidade), uma convergência de significação de toda realidade ôntica em um todo que é - o ser.

\begin{abstract}
A filosofia ocidental foi, na maioria das vezes, uma ontologia: uma redução do Outro ao Mesmo. [...] O seu sentido último tem a ver com a permanência no Mesmo, que é Razão. [...] O ideal da verdade socrática assenta, portanto, na suficiência essencial do Mesmo, na sua identificação de ipseidade, no seu egoísmo. A filosofia é uma egologia (LEVINAS, 1974: 13-14).
\end{abstract}

A obra de Levinas mostra-se como uma crítica aguda à redução que a totalidade impõe sistematicamente sobre a alteridade do outro, fazendo com que sua diferença, sua transcendência (infinito), seja condensada e suprimida em um conceito ou em um ato de poder, de força, de violência (totalidade). A analética, recolhendo os vestígios da escrita levinasiana (Cf. DUSSEL; GUILLOT, 1975), investe-se de um pensar metafísico como recusa à totalidade, ressaltando "o além", "o que está fora de" todo sistema hegemônico. Dussel aponta para o fato de que, na tradição filosófica, a ontologia - e o pensamento dialético - encontra-se associada à própria ideia de totalidade, essa "ideologia das ideologias do império" (DUSSEL, 1977, p. 11). Por conseguinte, Dussel proporá uma conversão ao pensar meta-físico, que seria a única forma de interromper a totalidade (DUSSEL, 1986, p. 199). Essa conversão à metafísica, que se faz tomar no sentido levinasiano do termo, enquanto ética como filosofia primeira, isto é, que "tem lugar nas relações éticas" (LEVINAS, 1974, p. 50-51) - relação com o transcendente tomada desde uma relação social -, é um movimento analético:

[...] entre os entes há um que é irredutível a uma de-dução ou de-monstração a partir do fundamento: o "rosto" ôntico do outro que, em sua visibilidade, permanece presente como trans-ontológico, meta-físico, ético. A passagem da totalidade ontológica ao outro como outro é ana-lética: discurso negativo a 
partir da totalidade, porque pensa a impossibilidade de pensar o outro positivamente partindo da própria totalidade; discurso positivo da totalidade, quando pensa a possibilidade de pensar e interpretar a revelação do outro a partir do outro (DUSSEL, 1986, p. 198).

Mais além da ontologia - na qual os entes permanecem mergulhados no horizonte do ser - e a identidade é pensada "como origem do mesmo que já se é” (DUSSEL, 1977, p. 54) - a filosofia da libertação faz insurgir a metafísica como discurso primeiro (ético por excelência), isto é, palavra analógica, ethos da libertação, em que o outro não se totaliza, pois está absolutamente separado (Cf. LEVINAS, 1974). O elo estabelecido entre o mesmo e o outro preserva uma positividade indispensável, do mesmo e do outro, por meio da separação, pressuposto basilar para a consolidação de um discurso que tem por objetivo último dizer o quê da ética, seu quem, sem a mácula da totalidade. Todavia, o além da totalidade não se descreve de um modo negativo. "A metafísica não coincide com a negatividade" (LEVINAS, 1974, p. 11). A relação ao outro pela separação é "uma impossibilidade de negar, uma negação da negação" (LEVINAS, 1998, p. 45). Trata-se de uma relação que se estabelece, sobretudo, através da escuta. "O filósofo ana-lético (ou ético) deve descer de sua oligarquia cultural acadêmica e universitária para saber-ouvir a voz que vem de mais além, do alto (aná-), da exterioridade da dominação" (DUSSEL, 1986, p. 199), pois é preciso considerar que a "voz-do-Outro foi [e é] retrotraída ao interior da Totalidade ontológica como mera 'voz da consciência'. (...) Perdendo a voz sua exterioridade real, o próprio ouvido foi sendo reduzido a mera metáfora" (DUSSEL, 1982b, p. 64). Escutar a voz do outro é libertá-lo da imposição do silêncio, desvelar de uma ideologia de dominação que age sob o signo de uma coerção sempre muda - seja ela política, erótica, pedagógica, religiosa e etc. O saber-ouvir acaba por constituir-se como "momento discipular do filosofar" (DUSSEL, 1982b, p. 203), atitude primeira do filósofo, âmbito da justiça, em que o "pensar não deve corroborar a alienação do Outro como 'o outro' oprimido dentro da Totalidade. Seu pensar deve ser um fator histórico do processo de libertação do Outro" (DUSSEL, 1982b, p. 60-61). Em destaque, pois, encontra-se uma noção de alteridade que diz sobre um encontro que se dá no face a face, em que o "mistério do outro revela-se por sua palavra, exigindo justiça." (DUSSEL, 1986, p. 227-228):

$\mathrm{Na}$ verdade, nós não somos, 'aquele outro, diferente da razão', mas, pelo contrário, o que pretendemos é manifestar eficazmente 'a razão do Outro'. (...) 
Pretendemos ser a expressão da 'Razão' dos que se situam bem além da 'Razão' eurocêntrica machista, pedagogicamente dominadora, culturalmente manipuladora, religiosamente fetichista. O que nós pretendemos é uma Filosofia da Libertação do Outro, isto é, daquele que está fora e distante dos horizontes desse mundo de hegemonias como o econômico-político (do fratricídio), da comunidade de comunicação real eurocêntrica (do filicídio), eroticidade fálica e castradora da mulher (do uxoricídio), e, não em último lugar, o do indivíduo que considera a natureza como mediação explorável para a valorização do valor capital (ecocídio) (DUSSEL, 1995, p. 46-48).

A "realidade do outro" se mostra dentro de um mundo concreto, prático, histórico, variável, dialético e não como uma essência não-histórica ou eterna. Trata-se de uma "subjetividade imediata", de uma corporeidade sofredora, sem recursos, sem alimento, sem capacidade para reproduzir sua vida, isto é, alguém pobre, explorado, silenciado. Nesse sentido, o outro, o tu, o próximo para Dussel é encarado como "exterioridade da razão, é existência real" (DUSSEL, 1982b, p. 196). Aí se encontra o ponto de partida da filosofia da libertação enquanto factum latino-americano, que se descreve como fato ético. Inspirando-se em Levinas, Dussel dirá que o Outro (todo e qualquer outro) encontra-se mais além do ser, mais além da cultura euro-norte-americana (Mesmo), que nega sistematicamente toda exterioridade, impedindo a singularização. Nesses termos, a filosofia da libertação volta seu discurso contra os princípios da exclusão, da miséria e da opressão - razão ética" (DUSSEL, 1995, p. 62). A crítica proposta por Dussel perpassa, por esse motivo, o acolhimento, a hospitalidade, a responsabilidade que se vê nascer diante da interpelação da alteridade excluída - exclusão que impõem ao discurso, ao argumento e à vida. E adverte ele que toda crítica que dispense esse atravessamento da alteridade torna-se, inevitavelmente, racionalidade de dominação (DUSSEL, 1995, p. 78). Pois, ou "a filosofia é autocrítica ou é um novo dogmatismo mistificador da realidade" (GULDBERG, 1983, p. 289).

Com efeito, subverter a ordem do "Mesmo" é o primeiro passo para o estabelecimento de uma ética da alteridade, de uma ética como filosofia primeira, uma vez que "o último horizonte da Totalidade não é ético ou moral, mas é simplesmente assim: como é" (DUSSEL, 1982b, p. 19) - dominador. O âmago dessa verdade que foi herdada do poema de Parmênides e que se consolidou como princípio para todo filosofar ao estabelecer a coincidência entre ser e pensar encontra-se em suspensão para a filosofia da libertação. Essa primazia do mesmo ou da identidade é comentada em Totalidade e infinito (1961) como o ensinamento que Sócrates nos legou: "Nada receber de Outrem a 
não ser o que está em mim, como se, desde toda a eternidade, eu já possuísse o que me vem de fora." (LEVINAS, 1974, p. 13-14). É preciso, pois, ultrapassar esta verdade tão antiga - sob "o risco de inverter certas noções que ao senso comum e à sabedoria das nações parecem as mais evidentes" (LEVINAS, 1982, p. 127) - que se faz perfilar no horizonte do ser, pois há mais que ser, há mais do que o sentido que se apresenta em seu horizonte. O sentido é o outro, encarado face a face, que se encontra fora de contexto e dos conteúdos rotulados de significações, à margem, que não estabelece relação com aquilo que é "visto" ou com o que é correlativo ao saber. Não se trata de um objeto da consciência que poderia ser medido em conformidade ao conhecimento que se absorve no ser e em sua luz. O privilégio da visão, daquilo que o "ver" oferece ao saber não é o ponto de partida para Dussel. Aponta-se para uma relação que não é da ordem do conhecimento, mas substancialmente ética. A defesa da invisibilidade é necessária para se preservar a exterioridade do rosto (visage). Afinal, "O visível forma uma totalidade ou tende para isso" (LEVINAS, 1974, p. 220). O "ver" não constitui a fonte última de legitimidade do sentido, essa visão que, desde Platão, "supõe além do olho e da coisa, a luz. O olho não vê a luz, mas o objeto na luz" (LEVINAS, 1974, p. 163). Encontra-se em destaque a possibilidade de estabelecer o pensar a partir da interpelação que extrapola as categorias da visão, da adequação, sob a inquietação irrecusável que vem do outro no face a face, essa porta de entrada da rebelião dos escravos, como diria Nietzsche (1998), que faz inserir um desarranjo na "lógica imperturbável da totalidade" (DUSSEL, 1982b, p. 40). Assim, a "alteridade é necessariamente rebelião" (DUSSEL, 1982b, p. 41) e a ética como ponto de partida volta-se para a libertação (conscientização), pensamento da práxis. Para Dussel essa ética originária se faz apresentar como prática política (-econômica), erótica, pedagógica e religiosa (Cf. DUSSEL, 1977). A ética possui uma dimensão de ação libertadora não sendo apenas discurso racional, acadêmico. Trata-se de um discurso que se insere e faz presença na vida cotidiana, nas circunstâncias dadas, exigindo ressignificação das estruturas historicamente totalizadoras e opressoras que excluem do mundo da vida o diferentemente situado de sua razão, o Outro que não-é, que não está no horizonte daquilo que se manifesta como verdade do ser, pois não se encontra aí como algo passível de ser "visto", é um invisível, um marginal, um excluído. Em jogo encontrase a afirmação do outro como outro e sua inviolabilidade absoluta (DUSSEL, 1982b, p. 28), amor de justiça à alteridade. 
Considera-se que a filosofia da libertação tem como ponto de partida a vida prática concreta (facticidade), sob uma dimensão de comprometimento e solidariedade com o oprimido (com o pobre explorado na periferia da cultura e da economia mundial). Essa corrente intelectual orgânica, que se traduz em uma práxis atravessada pela relação face a face, volta sua atenção para o sofrimento do outro, para o oprimido em sua concretude no instante em que se faz ouvir à consciência a voz de alguém que diz "eu estou sofrendo!", “tenho fome”. O oprimido tem nome: é o pobre, silenciado, o corpo precário, sofredor e necessitado. O problema não é filosófico, exclusivamente. É preciso repensar não apenas a primazia do sentido epistemológico que se dá à realidade ou que se recolhe dela, mas também o olhar que se lança à ordem econômica quando se depara com daqueles que se encontram subjugados - e a crítica à economia mostra-se como um dos elementos mais agudos da filosofia da libertação, pois não é possível conceber qualquer quebra da totalidade sem que se possa rever a ordem mundial que comanda toda miséria. Sem essa dimensão econômica, como ressalta Dussel, "tanto a 'hermenêutica' como a 'pragmática' ficam sem conteúdo 'carnal': são meras comunidades de comunicação ou de interpretação, sem caráter corporal ou carnal, isto é, sem subsumir em sua reflexão o nível da "vida"” (DUSSEL, 1995, p. 33). Nesse sentido, o "filósofo do Sul”, da periferia do mundo, deve considerar a miséria como questão para toda filosofia primeira, pois sem isso toda e qualquer hermenêutica se torna uma ideologia idealista e literalista - palavras vazias. Não se pode perder de vista o fato de que aqui na América Latina não temos apenas leitores diante de textos; e sim, fundamentalmente, famintos perante a mesa vazia. E o ter o que comer, ter pão é “critério absoluto para toda ética possível” (DUSSEL, 1986, p. 42). Não se pode pensar eticamente, filosoficamente ou mesmo propor a consolidação de uma nova cultura, de um novo mundo ou que for, quando há fome e miséria, quando a materialidade da vida não está garantida.

Para que esse projeto filosófico se faça possível é necessário, portanto, e por fim, acolher o outro, não esquivar-se de sua miséria ou de seu abandono, negando-o. Dussel utiliza-se da figura do profeta - que jamais rechaça o outro como falso - e analogamente compara-a ao ideal do modus vivendi do filósofo para dizer que "sua missão promotora da história o impele a libertá-lo [o não-ser], a conduzi-lo ao si mesmo autêntico como pro-jeto alheio, ao Outro, e não meu" (DUSSEL, 1982b, p. 46), pois “a indiferença é para o filósofo muito mais temível do que a morte, é sua verdadeira morte" (DUSSEL, 1982b, 
p. 166). Em outros termos, enfatiza-se a consolidação de uma nova subjetividade, assujeitada ao outro, assujeitamento (assujetssement) - movimento em que a subjetividade se afirma e se firma em sua doação, no acolhimento, na hospitalidade ao estrangeiro, ao excluído. O filósofo deve se voltar para o outro, inclinando seus ouvidos e seu coração, deixando que se cumpra em seu mundo a irrupção criadora do outro, deixando-se interpelar, chamar, inquietar, questionar por aquele que subverte a liberdade arbitrária da razão e exige justiça sempre. Pois, a práxis filosófica deve guiar-se pelo esforço de impedir toda ação e todo discurso que se voltam para a coisificação e aniquilação dos indivíduos - esse fetichismo da totalidade - por meio da opressão, da exploração, do silenciamento e etc. Para a filosofia da libertação, a práxis, eticamente situada, não é um modo de estar no mundo, mas $o$ modo de estar nele e de transcendê-lo, "é $o$ modo conjugado de todo o homem comprometido nas mediações para seu poder-ser sempre mundano. A práxis é o modo intramundano que reúne todo o ser do homem" (DUSSEL, 1982a, p. 89). Assim, pois, o "filósofo, aquele que quer pensar metodicamente, já deve ser um 'servidor' comprometido com a libertação" (DUSSEL, 1986, p 198). Trata-se de uma recuperação do sentido do compromisso que se dá após a superação do "espírito de sistema" (idealismo), pois o "idealista hegeliano" é descompromissado com a verdade do outro e só faz comtemplar o mundo pela via da indiferença, sempre com as mãos limpas (DUSSEL, 1982a, p. 85). Situada de um outro lado, a filosofia da libertação, inscrita sob uma trama de acolhimento ao outro e de uma analética dialógica, compreende que sua ação no mundo é luta por justiça e liberdade para aqueles que se encontram encobertos, esquecidos, invisíveis, à margem. "Descobrir a 'verdade' é ter, no atuar prático, identidade com os interesses dos oprimidos” (DUSSEL, 1986, p. 282). Essa, sim, é a verdade que liberta - ou pode libertar. O resto é alienação.

\section{Referências bibliográficas}

ALBERDI, J. B. Ideas para presidir a la confección del curso de filosofía contemporánea. Disponível em: $<$ https://biblioteca.org.ar/libros/104.pdf $>$ Acesso em 2 jun. 2021.

DUSSEL, E. D. Filosofia da libertação: crítica à ideologia da exclusão. São Paulo: Paulus, 1995. 
. Filosofia da libertação. São Paulo: Loyola/Unimep, 1977.

. Método para uma filosofia da libertação. São Paulo: Loyola, 1986.

- Para uma ética da libertação: acesso ao ponto de partida da ética. São

Paulo: Unimep, 1982a (Reflexão Latino-Americana; 2/I).

. Para uma ética da libertação: eticidade e moralidade. São Paulo: Unimep, 1982b (Reflexão Latino-Americana; 2/II).

DUSSEL, E. D.; GUILLOT, D. E. Liberación latinoamericana y Emmanuel Levinas. Buenos Aires: Bonum, 1975.

GULDBERG, H. C. Filosofía de la liberación latinoamericana. México: Fondo de Cultura Económica, 1983.

HEGEL, G. W. F. Introdução à história da filosofia. São Paulo: Abril, 1989. (Os Pensadores). . Princípios da filosofia do direito. São Paulo: Martins Fontes, 1997.

KONDER, L. Hegel: a razão quase enlouquecida. Rio de Janeiro: Campus, 1991.

LEVINAS, E. De l'évasion. Montepellier: Fata Morgana, 1982.

. Entre nous: essai sur le penser-à-l'autre. Paris: Grasset \& Fasquelle, 1998.

. Totalité et infini: essai sur l'extériorité. La Haye: Martinus Nijhoff, 1974.

NIETZSCHE, F. Genealogia da moral: uma polêmica. São Paulo: Companhia das Letras, 1998.

ZEA, L. América en la historia. Mexico: Fondo de Cultura Económica, 1957.

Recebido em: 30/06/2021 | Aprovado em: 05/08/2021 